Recebido: $11 / 01 / 2015$

Aprovado: 21/03/2015

\title{
James Harrington e a tradição republicana na Inglaterra do século XVII
}

\author{
Pedro Eduardo Batista Ferreira da Silva*
}

Resumo: O presente artigo analisa a obra The Commonwealth of Oceana, publicada em 1656, escrita por James Harrington. O objetivo do texto é trazer os principais elementos de Oceana, a qual não tem tradução para o Português. Ao entender Harrington como o primeiro humanista cívico da Inglaterra, reconhece-se a importância do autor para uma compreensão mais ampla dos eventos políticos que marcaram um século XVII inglês. A elaboração do artigo foi inspirada pelas leituras de importantes autores da chamada escola de Cambridge, como John Pocock e Quentin Skinner.

Palavras-chave: Republicanismo; Humanismo cívico; História das ideias; História do pensamento político

Abstract: The following article analyzes the work The Commonwealth of Oceana published in 1656 and written by James Harrington. The text purpose is to bring the main elements of Oceana which aren't translated to Portuguese. Understanding Harrington as the first civic humanist from England recognizes his importance for a larger understanding of the political events that had marked XVII century England. This article making was inspired by the reading of important authors from the Cambridge's school as well John Pocock and Quentin Skinner.

Keywords: Republicanism; Civic Humanism; History of Ideas; History of political thinking

\footnotetext{
* Graduado em História pela Universidade de Brasília. E-mail para contato: batistapedroeduardo@gmail.com
} 


\section{Um pouco sobre James Harrington e The Commonwealth of Oceana}

A vida de James Harrington é extremamente mal documentada. Pouco se sabe sobre o autor além daquilo que está em seus escritos. Nascido em 1611, o homem que se tornou um dos primeiros teóricos do republicanismo inglês frequentou durante pouco tempo uma instituição de educação formal. Não há registros de que tenha cursado uma escola básica e sabe-se apenas de sua breve passagem de dois anos pela Universidade Oxford, a qual abandonou sem diploma.

Boa parte do legado deixado por James Harrington teria sido perdido se não fosse pelo seu primeiro editor: John Toland. Em 1700, Toland publicou um primeiro volume no qual estão compilados os principais escritos de James Harrington e um breve resumo de sua vida. Segundo o maior especialista da obra de Harrington ainda vivo, o historiador John Pocock, Toland foi um editor confiável e um importante estudioso da vida e obra do republicano inglês ${ }^{1}$.

O texto analisado neste artigo, The Commonwealth of Oceana, é considerado a obraprima de James Harrington. Foi publicado pela primeira vez em 1656, durante o conturbado período das guerras civis inglesas e rendeu ao autor uma ordem de prisão. A obra idealiza uma constituição perfeita, pensada para reger uma república utópica.

The Commonwealth of Oceana divide-se três partes: um capítulo preliminar, no qual Harrington discorre acerca do conceito de prudência antiga; a segunda parte das preliminares, no qual o autor faz considerações sobre o conceito de prudência moderna; e a parte final, que ocupa maior espaço da obra, na qual é apresentado o modelo de república idealizado para este local imaginário, o qual o autor chama de Oceana.

Inúmeros especialistas na obra de Harrington, inclusive Pocock, reconhecem The Commonwealth of Oceana como parte da literatura utópica do século XVII. Apesar disso, Oceana não se revela uma utopia como as escritas por Thomas Morus ou Francis Bacon ${ }^{2}$. O texto é, em vários momentos, uma ficcionalização de uma ainda reconhecível Inglaterra.

Ao comentar sobre esse assunto, a pesquisadora Eunice Ostrensky é incisiva e afirma:

\footnotetext{
${ }^{1}$ Afirmação de John Pocock, contida no prólogo por ele escrito para a obra The Commonwealth of Oceana. HARRINGTON, James. The Commonwealth of Oceana and A System Of Politics (ed. J.G.A. Pocock). Cambridge: Cambridge University Press, 1992, p. IV.

2 Refere-se aqui aos clássicos de Morus e Bacon: A Utopia e Nova Atlântida. Vide referências: MORUS, Thomas. 1997. A Utopia. São Paulo: Nova Cultural. BACON, Francis. Nova Atlântida. Lisboa: Minerva, 1976.
} 
...o modelo de governo com o qual James Harrington atormentou seu cérebro não foi mera especulação ou, pior, fantasia e quimera. Harrington julgou ter oferecido a seus contemporâneos o único modelo de república que, por se basear nas peculiaridades da história inglesa, poderia impedir o recrudescimento de facções e interesses privados ainda remanescentes da monarquia gótica. ${ }^{3}$

The Commonwealth of Oceana é uma das primeiras obras representativas do republicanismo inglês. Outros textos contemporâneos à Oceana e que seguem a mesma linha são: The Excellency of a Free State, de Marchamont Nedham, e A Healing Question, de Henry Vane ${ }^{4}$. Ao mencionar tais obras, o historiador inglês Quentin Skinner destaca o fato de que todas elas, de alguma forma, enfocam o papel e a postura de Oliver Cromwell como um importante ator político da época ${ }^{5}$. Além disso, ainda segundo Skinner, todas argumentam em favor da ideia de que o regime republicano era o único adequado à Inglaterra e que o Protetorado $^{6}$ seria responsável por seu fracasso ou sucesso.

Este artigo se propõe a investigar as especificidades da concepção de república harringtoniana, tentando entender como a obra interage com seu contexto de produção.

Com este objetivo, do ponto de vista teórico-metodológico, dois autores foram fundamentais: John Pocock e Quentin Skinner ${ }^{7}$. Ambos enfatizam a importância de se considerar o contexto histórico na análise das linguagens e terminologias características do pensamento político. Ambos são considerados os principais expoentes da Escola de Cambridge como parte da História do Pensamento Político.

\section{James Harrington: o primeiro humanista cívico da Inglaterra}

O ano de 1641 é o marco do início de uma crise sem precedentes na história da Inglaterra. Entre 1641 e 1649, período de duração das guerras civis inglesas, predominava a incerteza quanto ao legitimo detentor da autoridade política no país. Uma série de discursos e

\footnotetext{
${ }^{3}$ OSTRENSKY, Eunice. As várias faces de um ator politico, p. 170.

${ }^{4}$ Ambos os textos citados são obras disponíveis em formato eletrônico na internet. Consultou-se aqui o sítio www.constitution.org, o qual apresenta um vasto acervo de textos de época.

${ }^{5}$ SKINNER, Quentin. Meaning and Understanding in the History of Ideas. In: History and Theory. Middletown - Wesleyan University, v.8, n.1, 1969, p.5.

${ }^{6}$ O termo Protetorado refere-se ao período em que Oliver Cromwell esteve no poder após receber o título de Lorde Protetor da Inglaterra. Durante tal período, Cromwell concentrou em suas mãos todas as atribuições do poder executivo.

${ }^{7}$ Foram referências os textos de POCOCK, J.G.A. The Machiavellian Moment. Princeton: Princeton University Press, 2001 e SKINNER, Quentin. Meaning and Understanding in the History of Ideas. In: History and Theory. Middletown - Wesleyan University, v.8, n.1, p. 3-53, 1969.
} 
propostas constitucionais surgiram nessa época e propunham solucionar a crise política local. O historiador inglês John P. Kenyon define este momento da história inglesa como a era do experimento $^{8}$.

Em uma releitura de Kenyon, ao tratar deste momento histórico, J. G. A. Pocock empregou a expressão momento maquiaveliano. De uma maneira simplificada, pode-se afirmar que essa a ocasião foi uma oportunidade histórica para a reflexão política. Inseridos nesse contexto, surgem os clássicos textos de James Harrington (The Commonwealth of Oceana) e Thomas Hobbes (Leviatã) ${ }^{9}$

Entendido por Pocock como o primeiro humanista cívico da Inglaterra, James Harrington compôs uma obra que analisou a história local por meio de uma linguagem e visão de mundo herdadas de Nicolau Maquiavel. Harrington afirmou que Maquiavel, apesar de ter cometido equívocos em algumas de suas propostas, era o único intelectual da época moderna que ainda estava ligado à perfeição do mundo antigo. Além disso, Harrington lamentou o fato de os livros de Maquiavel terem sido negligenciados em favor do Leviatã, de Thomas Hobbes. Uma vez que esse artigo inspira-se na interpretação de J.G.A. Pocock, James Harrington é entendido aqui como um dos autores que difundiram o humanismo cívico no século XVII.

Conceito complexo, o humanismo cívico foi sintetizado com precisão pelo professor de Filosofia Política da Universidade de Paris I, Jean-Fabien Spitz, na introdução francesa de The Machiavellian Moment, de J.G.A. Pocock. Para Spitz:

As palavras de ordem dessa 'outra linguagem' da política moderna são pois: república, autonomia, espírito cívico, recusa do luxo, e dos exércitos mercenários, repúdio da especialização das funções e da representação, elogio da participação ativa de todos os cidadãos na defesa e no exercício do poder, graças à renovação frequente das assembleias efetivas, à rotação das funções, à recusa dos exércitos permanentes, e às precauções multiplicadas para evitar que os governantes cedessem à corrupção ao utilizar suas funções políticas para fins privados. ${ }^{10}$

\footnotetext{
${ }^{8}$ Afirmação contida no texto de OSTRENSKY, Eunice. As várias faces de um ator político. In: Revista Latinoamericana de Filosofía. Buenos Aires, v.37, n.2 (Primavera 2011), 2011, p.168.

${ }^{9}$ HARRINGTON, James. The Commonwealth of Oceana and A System Of Politics (ed. J.G.A. Pocock). Cambridge: Cambridge University Press, 1992 (texto publicado em 1656) e . HOBBES, Thomas. Leviatã ou matéria forma e poder de um Estado eclesiástico e civil. Tradução João Paulo Monteiro e Maria Nizza da Silva, Martins Fontes, São Paulo, 2003.

${ }^{10}$ SPITZ, Jean-Fabien. Introdução à edição francesa de The Machiavellian Moment, Paris, PUF, 1987. pp. VIIVIII.
} 
A partir do entendimento do conceito de humanismo cívico, fica mais fácil entender a solução constitucional idealizada por James Harrington para a Inglaterra do século XVII. Em linhas gerais, os elementos acima citados estão todos presentes no pensamento harringtoniano.

\section{A reflexão preliminar de Harrington: os elementos de um governo}

A história parece ser algo muito importante para James Harrington. Tal zelo histórico fica demonstrado porque, apesar da pressa em publicar The Commonwealth of Oceana, em 1656, o autor baseou toda a sua argumentação em um amplo panorama histórico da realidade política do ocidente, desde a antiguidade até o século XVII.

Nas páginas iniciais de sua obra, o filósofo político inglês cita Donato Gianotti, escritor político italiano e um dos líderes da República Florentina de 1527. Gianotti, um teórico do republicanismo, dividiu os governos do mundo ocidental em dois momentos: um anterior ao fim da liberdade em Roma, período que Harrington define como o da prudência antiga; e outro que começa com César, líder que, ao extinguir a liberdade dos cidadãos, assinalou a transição entre a prudência antiga e a prudência moderna ${ }^{11}$.

Harrington era um pensador fortemente ligado à tradição antiga e argumentou que, para a existência uma república ideal, uma série de elementos do mundo antigo deveriam ser resgatados. Ele tinha um imenso fascínio pela sabedoria política dos antigos que, segundo ele, surgiu da república de Israel - fundada por Deus, e posteriormente teve como seguidores os gregos e romanos.

De acordo com Harrington foi essa sabedoria política que permitiu a longa duração dos regimes republicanos antigos, dentre os quais se destacam o de Israel, bem como os dos mundos grego e romano. A perpetuação de tais regimes foi abalada principalmente pelas invasões bárbaras.

A chegada dos povos bárbaros é identificada por Harrington como um dos grandes problemas do passado. Segundo o historiador inglês Christopher Hill, na visão de história de James Harrington, as invasões bárbaras assinalam um segundo momento e estabelecem aquilo que o autor intitulou balanço gótico.

\footnotetext{
${ }^{11}$ A prudência antiga é sempre examinada em oposição à prudência moderna. Segundo Harrington, a prudência moderna caracteriza um governo no qual alguns homens, sujeitam uma cidade ou uma nação às suas regras e interesses pessoais. Devido ao fato de as leis serem elaboradas de acordo com o interesse de um homem ou algumas poucas famílias, há aqui um império de homens e não de leis.
} 
Durante o período de vigência desta forma de equilíbrio do poder, o controle político e militar esteve concentrado nas mãos de uma aristocracia. Desse modo, as monarquias góticas, predominantemente aristocráticas, foram o grande marco dos tempos medievais.

Assim, entende-se por que Donato Gianotti é um exemplo para James Harrington. Segundo o escritor de Oceana, o único local que teria ficado imune a essa invasão e deformação do mundo foi Veneza. Para ele, Veneza sempre se manteve atada à prudência antiga e à perfeição.

\section{As prudências em Harrington: antiga e moderna}

Prudência é uma das palavras que mais aparecem nas páginas iniciais de The Commonwealth of Oceana e a distinção entre dois tipos de prudência que norteia a reflexão inicial de James Harrington sobre o governo ideal.

Primeiramente, deve-se salientar que Harrington entende esse conceito da mesma forma que Thomas Hobbes. Para ele, prudência é a capacidade que os governantes têm de prever o futuro com base em experiências passadas e, a partir disto, fazer uso de sua autoridade de maneira mais consciente. Os líderes do governo reúnem algumas características que não estão presentes no povo. Uma delas é a prudência.

Desse modo, é plausível frisar que nos tempos da prudência antiga, o governo era uma arte por meio da qual uma sociedade de homens era instituída e preservada sobre os alicerces do direito e do interesse comum, ou seja, é um império de leis e não de homens ${ }^{12}$.

Além disso, Harrington compartilhou da opinião dos teóricos da antiguidade quando afirmou que, de acordo com eles, os princípios do governo são dois: um interno (os bens da mente) e outro externo (os bens da fortuna). Os bens da mente consistiam nas coisas adquiridas naturalmente: sabedoria, prudência e coragem; já os bens da fortuna eram as riquezas materiais.

No que diz respeito aos bens da fortuna, o pensador alegou que sua existência era inevitável. Contudo, a riqueza material costumava corromper o homem; era necessário um balanço para que isso não acontecesse. É exatamente neste ponto que reside uma das maiores preocupações de Harrington: a corrupção no exercício do poder.

\footnotetext{
${ }^{12}$ HARRINGTON, James. The Commonwealth of Oceana., p.9. 
A única maneira de se evitar a corrupção seria a introdução de um regime de governo misto no qual todos participassem e deliberassem, bem como reconhecessem as virtudes uns dos outros. Assim, a razão predominaria sobre a paixão e bom governo prevaleceria.

Ainda nessa linha de raciocínio, James Harrington vislumbrou, apoiando-se nos antigos e em Maquiavel, o último verdadeiro discípulo deles, que um governo poderia assumir três formas: o governo de um só homem (monarquia); o governo de um grupo específico de pessoas (aristocracia); o governo de todo um povo (democracia). Harrington afirmou que o homem estava sempre entre a razão e a paixão e toda vez que a razão era corrompida pela paixão, o bom governo degenerava-se. A degeneração de uma monarquia desencadeava a tirania; a corrupção de uma aristocracia, a oligarquia; e, por fim, uma democracia, quando corrompida, transformava-se em anarquia.

James Harrington entendeu que nenhuma dessas formas de governo é perfeita e sustentou que os legisladores antigos, tendo percebido isto, inventaram outra que consistiria em uma mistura das três: a doutrina dos ancestrais ${ }^{13}$.

\section{Oceana em oposição ao Leviatã: um contra-ataque}

Sabe-se que The Commonwealth of Oceana foi publicado às pressas. Segundo a pesquisadora Eunice Ostrensky, isso foi feito ainda que o autor temesse que a obra não passasse de um rascunho repleto de erros. De acordo com Ostrensky:

É o próprio autor quem parece se colocar essa urgência, na tentativa de fornecer uma resposta rápida aos desdobramentos da vida política inglesa naquela quadra de 1650 . Já no início da década, o experimento republicano havia fracassado, resultando no governo oligárquico de facto do Rump. Mas, quando Cromwell dissolveu o Rump e convocou um novo parlamento, ficou claro que os diferentes poderes políticos do país, ao invés de se dividirem, tendiam para o centro, tendiam para Oliver Cromwell e seu grupo de apoio. ${ }^{14}$

A passagem acima conduz a uma reflexão muito interessante. É muito provável que a pressa de Harrington em publicar o livro decorra da impressão de que o momento maquiaveliano (ou seja, de instauração de um regime republicano) das revoluções parecia já ter passado. J.G.A. Pocock afirma que o momento maquiaveliano aconteceu entre 1649 e 1653; entretanto, a dissolução do parlamento e o golpe militar de 1653 teriam inaugurado um

\footnotetext{
${ }^{13}$ Livre tradução do termo The doctrine of ancients usado por James Harrington em Oceana.

${ }^{14}$ OSTRENSKY, Eunice. As várias faces de um ator político, p. 169.
} 
novo momento da revolução: o hobbesiano. Segundo o historiador Jonathan Scott, 1653 representa o fim do experimento republicano na Inglaterra.

É por este motivo também que, em muitos momentos, The Commonwealth of Oceana pode ser interpretado como uma oposição ao Leviatã de Hobbes. Essa obra é ironizada por Harrington inúmeras vezes no corpo de seu texto. Uma das maiores críticas de Harrington ao filósofo político Thomas Hobbes de Malmesbury é o fato de seu pensamento ter sido aceito como uma verdade única e absoluta e seus livros adotados nas universidades.

O regime cromwelliano revelava-se cada vez mais semelhante a uma monarquia. Não se sabe se Cromwell imaginou um dia tornar-se um rei, mas sua postura era cada vez mais autoritária e centralista. Cromwell ia, a passos largos, aproximando-se do modelo desenhado por Hobbes.

Harrington via Hobbes como um destruidor da prudência antiga por perceber os pensadores antigos de uma maneira muito genérica, ignorando suas peculiaridades. Uma das objeções do teórico do republicanismo ao texto de Hobbes era o fato de o Leviatã reconhecer como legítima apenas uma forma de governo: a monarquia.

James Cotton, em texto publicado no Journal of the History of Ideas, da Universidade da Pensilvânia, afirma que Harrington reconhece Hobbes como um intelectual inovador e inspirador; contudo, tem mais objeções do que elogios ao seu texto ${ }^{15}$.

Tanto Oceana como o Leviatã ressaltam o peso dos proprietários ricos na estrutura de organização do poder. Os dois textos concordam que riqueza é poder. No entanto, para Harrington, a concentração de riqueza não está diretamente ligada ao exercício da autoridade. É a partir dessa premissa que Harrington estrutura sua doutrina do balanço da propriedade.

\section{A especificidade do pensamento harringtoniano}

O balanço do poder por meio do equilíbrio das riquezas, distribuição das terras e lei agrária. Lê-se sem Harrington:

Um império doméstico é fundado a partir da dominação.

A dominação é propriedade real ou pessoal; seja em terras, em dinheiro ou em bens.

As terras, ou parcelas do território, são mantidas por um proprietário ou proprietários, um senhor ou senhores dela, em alguma proporção

\footnotetext{
${ }^{15}$ COTTON, James. James Harrington and Thomas Hobbes. In: Journal of the History of Ideas. Philadelphia,
} v.42, n.3, pp. 407-421, 1981. 
(...) e, a natureza do império depende do balanço do domínio da propriedade. ${ }^{16}$

Ou seja, para Harrington, a dominação de um homem sobre o outro era baseada na maior parte das vezes a partir da posse de alguma propriedade material: terras, dinheiro ou outros tipos de riquezas. Desse modo, em outra passagem, Harrington relaciona a posse e distribuição da terra à legitimidade de determinadas formas de governo.:

Se um homem apenas é proprietário da terra, ou desequilibra o balanço em relação ao povo, por exemplo, domina três quartos dos latifúndios, então, neste caso, ele é grand signor (...) e seu império é uma monarquia. Se alguns poucos, ou a nobreza, ou a nobreza com o clero, são proprietários das terras e desequilibrem a balança, há o balanço gótico e o governo é uma monarquia mista (...), como as da Espanha, Polônia e a recente Oceana. ${ }^{17}$

Nessa passagem Harrington sugere que a Oceana a qual se refere é a Inglaterra dos séculos XVI e XVII. Recorrendo novamente à pesquisadora Eunice Ostrensky, pode-se dizer que, na concepção de James Harrington, a corrupção dos governos não aconteceria na imaginação dos homens e sim na carne do regime. Segundo o pensador inglês, com o tempo os governos apodreceriam como acontece com toda a matéria do mundo.

Harrington refletiu que os homens estariam atados aos seus bens materiais uma vez que precisavam de pão para viver. Assim, se um homem alimentava todo um povo, este estaria sob o seu império. Era exatamente por isso que, na concepção harringtoniana de governo ideal, a terra seria dividida e a perpetuação do regime dependeria da manutenção desse equilíbrio.

Foi a partir dessa lógica que Harrington explicitou a condição da terra em seu modelo constitucional:

Caso todo o povo seja senhor da terra, ou caso as mesmas estejam divididas entre eles, e desde que nenhum homem, ou um grupo de homens, incluindo os poucos da aristocracia, alterem o equilíbrio da

\footnotetext{
${ }^{16}$ HARRINGTON, James. The Commonwealth of Oceana., p. 11. "Dominion is property real or personal; that is to say in lands, or in money and goods. Lands, or the parts and parcels of a territory, are held by the proprietor or proprietors, lord or lords of it, in some proportion; and such (except it be in a city that hath little or no land, and whose revenue is in trade) as is the proportion or balance of dominion or propriety in land, such is the nature of the empire".

${ }^{17}$ HARRINGTON, JAMES. The Commonwealth of Oceana., pp. 11-12. "If one man be sole landlord of a territory, or overbalance the people, for example, three parts in four, he is grand signor (...), and his empire is absolute monarchy. If the few or a nobility, or a nobility with the clergy, be landlords, or overbalance the people unto the like proportion, it makes the gothic balance and the empire is mixed monarchy as that of Spain, Poland and late Oceana.
} 
distribuição das terras, o Império (que não se utiliza da força) é uma república. ${ }^{18}$

Com isso, percebe-se que a relação dos homens com a terra e a propriedade era uma das maiores preocupações do autor.

Nessa linha, Harrington ainda propôs uma lei agrária, a qual considerava essencial à consolidação e permanência de um governo republicano. De acordo com ele, a primeira lei agrária foi introduzida por Deus, quando dividiu Canaã e distribuiu sua terra ao povo.

Bastante virtuosa, a lei agrária sobreviveu a vários governos e foi alterada poucas vezes, sempre por consenso. De acordo com Harrington, sem uma lei de regulação da terra, governos (fossem eles monárquicos, aristocráticos ou populares) jamais teriam longa duração.

\section{Primazia das leis e manutenção do regime misto: o senado como propositor e espaço de deliberação}

Todo o corpo dos regulamentos a serem aplicados no modelo republicano idealizado por James Harrington seria discutido no senado. Para o autor, o senado nada mais era do que o local de debate na república. Sobre a fundação dessa instituição, Harrington afirmou que os senadores não assumiriam seus cargos por hereditariedade; eles seriam escolhidos a partir de suas virtudes e talento natural para liderança.

Para entender o acima exposto é necessário acompanhar o pensamento do filósofo político inglês e seu ideal de que uma república é uma sociedade civil de homens. Após fazer essa afirmação, Harrington sugere ao leitor que imagine uma república com vinte homens. Ele afirma que, caso esses vinte homens não sejam completamente estúpidos, um terço deles, ou seja, seis homens seriam um pouco mais espertos que os demais. Esses se destacariam e seriam imediatamente descobertos e tidos como os líderes.

Essencial notar que a partir de seus debates, esses líderes transmitiriam conhecimento aos quatorze demais e, por meio de suas decisões, convenceriam aqueles a segui-los. Esses seis fariam uso daquilo que se entende por auctoritas patrum, isto é, a autoridade dos pais. Eles não são nada mais do que a aristocracia natural, criada e difundida por Deus para liderar a humanidade. É exatamente esta parcela da população que comporia o senado. Uma vez definidos os membros do senado, é essencial fixar o seu papel perante a sociedade.

\footnotetext{
${ }^{18}$ HARRINGTON, JAMES. The Commonwealth of Oceana., p.12. "And of the whole people be landlords, or hold the lands so divided among them, that no men, or number of men, within the compass of the few aristocracy, overbalance them, the empire (without the interposition of force) is a commonwealth.
} 
Esses senadores, apesar de líderes, não seriam comandantes. Eles apenas guiariam a população e liderariam a consulta ao povo. Na república harringtoniana, os decretos do senado nunca eram tidos como lei e não deveriam ser assim denominados. Os textos lá produzidos inspirar-se-iam no senatus consultum da república romana e eram uma espécie de parecer coletivo, proposto pelos homens do governo e posteriormente aprovado ou não pelo povo. No modelo harringtoniano, os senadores fariam uso de sua virtude natural em prol da população; eles filtrariam os problemas e apresentariam soluções ao povo, mais ou menos como pais a instruir filhos.

A eleição do senado seria realizada por meio do voto popular. Harrington via o senado como a razão de uma república; contudo, seu papel ficaria restrito à função legislativa. Não era o senado que deveria definir os interesses da república. Estes seriam comuns a todos e manteriam ativa a república harringtoniana.

A partir dessas considerações, o autor concluiu que se a sabedoria de um governo republicano estava na aristocracia, cujo interesse coincidiria com o de toda a população. Logo, a assembleia, ou o conselho a escolher o senado, deveria ser constituído por todo o povo.

Segundo Harrington, na linguagem de uma república, dividir e escolher é debater e resolver; portanto, os debates do senado deveriam ser levados ao povo, e após essa consulta popular, retornariam para serem resolvidos pelos senadores, seguindo a filosofia institucional auctoritate patrum et jussu populi; isto é, a autoridade dos pais e do povo, juntas, fazem a lei.

\section{A magistratura}

James Harrington refletiu inicialmente sobre duas ordens legislativas da estrutura republicana de poder: o senado e o povo. Assim, fazia-se necessária a existência de uma terceira ordem do poder: a executiva. Foi aqui que Harrington se deparou com mais um dilema na elaboração da estrutura de um governo republicano: quem executaria o corpo de leis e normas?

Com isso, ficou definido o papel da magistratura. A execução das leis seria feita por esse grupo, o último a completar a divisão de poder no modelo republicano em questão. Lê-se em Harrington: 
...uma república consiste no senado propondo, o povo resolvendo e a magistratura executando em um sistema no qual o papel da aristocracia é feito pelo senado, da democracia pelo povo e da monarquia pela magistratura. ${ }^{19}$

Assim, está colocada a forma institucional da república harringtoniana. James Harrington afirmou que nenhuma república na história foi capaz de realizar o proposto por ele. Segundo o autor, Veneza foi a que chegou mais perto. Tal afirmativa foi justificada pelo argumento de que Veneza teve um sistema de leis não muito claro e também pelo fato de que a magistratura veneziana sempre esteve concentrada na mão de poucos. De acordo com Harrington, o próprio Donato Gianotti confessara isso em seu Libro della repubblica de'Viniziani ${ }^{20}$.

Sobre esse último ponto, James Harrington lembrou que a rotatividade da magistratura deveria ser uma das maiores preocupações em uma república. Segundo ele, a prolongação da magistratura destrói a vida, o movimento natural de uma república.

Por esta forma, percebeu-se a razão pela qual a República Veneziana falhou no reconhecimento universal da virtude. Tendo existido concentração do poder e baixa rotatividade da magistratura, Veneza não se alinhou a um dos princípios básicos do pensamento harringtoniano: o de que uma república é um governo de leis e não de homens; portanto, baseia-se no princípio da virtude e não do homem.

\section{Oceana como um discurso para a gentry}

O século XVII inglês viu a ascensão de um grupo social especial: a gentry. O termo oriundo do francês arcaico, genterie, conecta-se também ao latim, gentil, e denota uma classe de iguais, distintos dos demais por serem bem-nascidos e pertencentes a uma posição social superior. Na Inglaterra dos anos 1600, a gentry era uma espécie de elite latifundiária e era uma aristocracia por excelência, pois não possuía títulos de nobreza. A gentry se consolidou como superior em virtude das propriedades que acumulou.

\footnotetext{
19 HARRINGTON, JAMES. The Commonwealth of Oceana., p.25. “...the commonwealth consisteth of the senate proposing, the people resolving, and the magistracy executing, whereby partaking of the aristocracy as in the senate, of the democracy as in people, and of the monarchy as in the magistracy...".

${ }^{20}$ GIANOTTI, DONATO. Libro della repubblica de'Viniziani. Roma, 1540.
} 
Durante a Idade Média, em cidades livres como Veneza e Genova, os grupos conectados à posse da terra foram à elite governante e viram seus membros assumirem controle da máquina burocrática do estado.

Feita essa associação, percebe-se aqui um aspecto no qual James Harrington inspirouse na república veneziana. Para o autor, apenas a gentry poderia, no momento de fundação da república harringtoniana, oferecer um líder ou grupo de líderes ao povo. Apenas um gentleman reuniria as características necessárias para tornar-se príncipe, no sentido maquiaveliano da palavra. Isso ajuda a entender a razão pela qual James Harrington considerava a monarquia absoluta radicalmente distinta da república.

Ao longo dos séculos XVI e XVII, na Inglaterra, a lógica de uso e propriedade da terra começou a se transformar. Lentamente, a gentry começou a ampliar seu domínio sobre as terras. Em alguns momentos do texto, Harrington dá pistas de que a percepção que se tinha da gentry como um grupo superior ao povo era incorreta. Segundo o autor, nesse momento da história inglesa, havia embutido na gentry um medo do povo e vice-versa. Essa percepção equivocada era um obstáculo à fundação harmoniosa de uma república.

Pode-se então dizer que o intelectual inglês entendia a gentry como uma parcela do povo. Seria da gentry que viriam os grandes políticos, legisladores, cônsules e administradores públicos. O conflito de interesses que se viu durante as guerras civis era estúpido e não parecia, de forma alguma, ser o motivo para a crise dos anos 1650. Harrington teorizou que a gentry era a alma de uma república já que, no momento de sua fundação, apenas o gentleman teria as qualidades necessárias para a realização de tal feito.

Três coisas distintas são: fazer uma república, depois governa-la e, por último, liderar o seu exército que, apesar da existência de grandes deuses, grandes juristas, grandes homens em todas as profissões, é tarefa peculiar dos gentlemen. Algo universal na história é que se algum homem fundou uma república ele era, primeiramente, um gentleman. Moisés foi educado pela filha de um faraó, Teseu e Solon, ambos de berço nobre, foram julgados como dignos de serem reis pelo povo de Atenas; Licurgo tinha sangue real, Romulo e Numa (Pompílio) foram príncipes, Brutus e Públio patrícios (...). E o reconhecido Olphaus Megaletor, único legislador (como vocês verão) de Oceana, veio de uma família nobre. ${ }^{21}$

\footnotetext{
${ }^{21}$ HARRINGTON, James. The Commonwealth of Oceana., p.36. "There is something first in the making of a commonwealth, then in the governing of her, and last of all in the leading of her armies, which, though there be great divines, great lawyers, great men in all professions, seems to be peculiar to the genius of a gentleman. For so it is in the universal series of [history], that if any man have founded a commonwealth, he was first a gentleman. Moses had his education by the daughter of Pharaoh; Theseus and Solon, of noble birth, were held by the Athenians worthy to be kings; Lycurgus was of the blood-royal; Romulus and Numa princes; Brutus and
} 
Nota-se assim que, na opinião de Harrington, o gentleman do século XVII era o modelo de homem ideal: livre e proprietário de terras. Foram esses cidadãos, gente habituada à difícil vida no campo, que lutara contra a monarquia absoluta em prol de um regime completamente novo, capaz de defender seus interesses.

A desigualdade nas classes vinculadas a terra já existia na Inglaterra muitas décadas antes das guerras civis; entretanto, foi somente na década de 1650 que os descontentes organizaram-se militarmente contra a coroa e na defesa de um governo mais popular.

Interpretações mais recentes acreditam que essa foi a chance dos ingleses implementarem uma república. Foi esse o momento maquiaveliano das revoluções na Inglaterra. Tendo percebido isso, Harrington correu para publicar seu livro. Tudo foi feito com urgência, às pressas. $\mathrm{O}$ autor compôs um discurso que teve a intenção de chamar a atenção da gentry para a oportunidade que se esvaia.

\section{Oliver Cromwell e Oceana}

Uma das figuras mais emblemáticas da história da Inglaterra dos anos 1600 foi Oliver Cromwell. Eleito membro do Parlamento em 1628, Cromwell rapidamente juntou-se aos roundheads $^{22}$ nas guerras civis. Sua vertiginosa ascensão de político à líder militar fez dele um ícone na deposição de Carlos I e instauração do Rump em Londres.

O governo parlamentarista do Rump vigorou entre 1649 e 1653 e teve como líder Oliver Cromwell. É nesse estágio da história inglesa que se reconhece o governo local como uma república.

Cromwell liderou a Inglaterra em algumas campanhas militares durante esse período e tentou implementar algumas mudanças políticas. Contudo, a experiência do Rump não foi das melhores para o político britânico. As deliberações nem sempre aconteciam como ele queria e, em 1653, à força, dissolveu o Parlamento.

Oliver Cromwell é tido como uma das figuras mais controversas da história local. Um dos maiores especialistas sobre a vida de Cromwell, o historiador David Sharp, observou que

Publicola patricians (...). And the most renowned Olphaus Megaletor sole Legislator (as you will see) of the Commonwealth of Oceana, was derived from a noble family."

${ }^{22}$ Roundheads foi como ficaram conhecidos os defensores do regime parlamentarista durante as guerras civis inglesas. Ao lutar contra os royalists, defensores da monarquia, manifestavam-se contra a teoria do direito divino dos reis e pregavam uma mudança radical no sistema político. 
as opiniões acerca do líder político oscilam de um extremo ao outro. Intelectuais como David Hume e Christopher Hill o descrevem como um ditador regicida; já escritores como Samuel Gardiner e Thomas Carlyle o entendem como um herói libertador ${ }^{23}$.

James Harrington tinha duas opiniões distintas sobre Cromwell. Ele admirava o Cromwell republicano, aquele que ajudou a estruturar o Rump e lutou ao lado da gentry. É crucial frisar que Oliver Cromwell era um membro da gentry e defendia uma participação mais ativa dos gentlemen no governo bem como a defesa de seus direitos. $\mathrm{Na}$ visão de Harrington, o Cromwell que lutou nas campanhas na Escócia e Irlanda reunia as características essenciais a um príncipe. Era um gentleman, carismático, ligado à terra, ao exército e à política.

A crítica a Cromwell surgiu quanto este se deixou corromper pelos reveses da fortuna. Ao se falar de fortuna, é primordial levar em consideração que Harrington entendia fortuna como sorte, acaso ou contingência. Nota-se que Cromwell acumulou riquezas e poder; além disso, aproveitou-se de sua popularidade e credibilidade para organizar um golpe e estabelecer um regime centralizador após a dissolução do Rump. Definitivamente, não eram essas as expectativas de Harrington em relação a ele. Esse é um dos motivos pelo qual o Lorde Protetor da Inglaterra foi muitas vezes criticado e satirizado por Harrington em The Commonwealth of Oceana.

Cromwell atendeu por dois pseudônimos em Oceana e conhecê-los contribui para um melhor entendimento da obra. Primeiramente, um dos nomes representa o Cromwell bom, patriota e capitão vitorioso enquanto o outro fala do falso republicano que arquitetou um golpe e centralizou as atribuições do poder executivo em suas mãos.

As características da face boa de Cromwell, ou seja, o líder patriota e vencedor aparecem reunidos em seu primeiro pseudônimo: Olphaus Megaletor. Em contrapartida, o lado ruim, assíduo na obra, manifesta-se em Lorde Archon. Em grego, archon, era a palavra usada para tratar líderes de governo e burocratas de Estado. Em várias cidades do mundo grego antigo, o archon era o magistrado local.

Segundo Eunice Ostrensky, pudesse de fato ser identificado como Lorde Archon, terse-iam mais elementos para afirmar que Oceana é indubitavelmente uma ficcionalização da Inglaterra. De acordo com a autora:

${ }^{23}$ SHARP, David. Oliver Cromwell. London: Heinemann, 2003. 
Se Cromwell puder ser identificado a Lorde Archon, tenderíamos a concluir que Oceana teria sido escrito para nortear as ações de Cromwell nessa grande empreitada histórica proporcionada pela fortuna: a criação de uma república em moldes modernos na Inglaterra. Esse "momento maquiaveliano" teria então em Cromwell um de seus principais líderes. ${ }^{24}$

Nessa linha, Ostrensky ressalta o perigo de se dizer que o codinome Lorde Archon refere-se somente a Oliver Cromwell. Cautelosamente, a pesquisadora brasileira prefere acreditar que essa metáfora talvez não diga respeito somente a Cromwell, mas também a vários outros protagonistas da história política inglesa.

De maneira precisa, a autora destaca que o importante não é a quem o pseudônimo se refere e sim o fato de que James Harrington estava alertando os leitores para a possibilidade de que a Inglaterra viesse a perder a rara, senão única, oportunidade de se converter em uma república.

\section{Um texto para a história: considerações finais}

A Inglaterra de fato perdeu a oportunidade de se converter em uma república. O modelo harringtoniano nunca foi utilizado em solo britânico. Muito pelo contrário. Seu texto rendeu-lhe uma longa estadia na prisão. Harrington foi levado para a Torre de Londres em 1661 e lá permaneceu acusado de conspirar contra o regime.

Com a morte de Cromwell e a restauração monárquica na Inglaterra, as ideias republicanas foram ignoradas e deixadas para trás. Estava cada vez mais claro que a Inglaterra caminhava para a Revolução Gloriosa de 1688 e a restauração por ela proposta.

Nota-se que Harrington foi um pensador preocupado com a igualdade entre as partes em um sistema político. A ideia de igualdade em Harrington é um tanto paradoxal uma vez que Harrington deixa bastante claro que dificilmente um membro das camadas mais baixas chegaria ao poder. Ele entendeu que todos tem o mesmo peso nas deliberações; contudo, somente alguns mais virtuosos chegariam aos cargos altos da administração pública. Essa virtude estaria, no momento da fundação da república, presente nos gentlemen.

Destarte, as palavras autoridade e poder ganham no pensamento harringtoniano uma importância inegável. Para o autor, a autoridade é concedida aos líderes pelo povo, é uma cessão feita a alguém mais virtuoso. Esse alguém, estando comprometido com os princípios

\footnotetext{
${ }^{24}$ OSTRENSKY, Eunice. As várias faces de um ator politico., p. 171. 
básicos da república, deve fazer uso virtuoso da autoridade e não deixar que os bens da fortuna ou a paixão humana corrompam o exercício do poder. Tudo deve ser feito em prol da coletividade e da igualdade. Em suma:

Uma república igualitária é igual tanto no balanço ou fundação quanto nas superestruturas, isto é, na lei agrária e sua rotatividade. Uma lei agrária é uma lei perpétua que estabelece e preserva o balanço da dominação, de maneira que nessa distribuição nenhum homem ou grupo de homens dentre a aristocracia pode ser mais poderoso do que o povo no que diz respeito às posses da terra. A lei agrária respondeu à fundação assim como a rotatividade às superestruturas. Uma rotatividade equilibrada é a aleatoriedade no governo (...). O contrário é, contudo, a prolongação da magistratura que destrói a vida, o movimento natural da república. ${ }^{25}$

\section{Referências Bibliográficas}

\section{Fonte:}

HARRINGTON, James. The Commonwealth of Oceana and A System Of Politics (ed. J.G.A. Pocock). Cambridge: Cambridge University Press, 1992.

\section{Bibliografia:}

APPLEBAUM, Robert. Literature and Utopian Politics in Seventeenth Century England. Cambridge: Cambridge University Press, 2004.

ARAÚJO, Cícero. A angústia republicana - entrevista com J.G.A. Pocock. In: Lua Nova: Revista de Cultura e Política. São Paulo, n.51, pp. 31-40, 2000.

BEIRED, José Luis Bendicho. Vertentes da História Intelectual. In: Cadernos de Seminário Cultura e Política nas Américas. São Paulo, v.1, pp. 86-98, 2001.

CROMARTIE, Alan. Harringtonian virtue: Harrington, Machiavelli and the method of the moment. In: The Historical Journal. Cambridge, v.41, n.4, pp 987-1009, 1998.

COTTON, James. James Harrington and Thomas Hobbes. In: Journal of the History of Ideas. Philadelphia, v.42, n.3, pp. 407-421, 1981.

FLORENZANO, Modesto. J.G.A. Pocock e a reavaliação do discurso político moderno. In: Cadernos de Seminário Cultura e Política nas Américas. São Paulo, v.1, pp. 6-19, 2001.

HILL, Cristopher. Puritanism and Revolution: Studies in Interpretation of the English Revolution of the $17^{\text {th }}$ Century. New York: St. Martin's Press, 1997.

\footnotetext{
${ }^{25}$ HARRINGTON, James. The Commonwealth of Oceana., p.33. "An equal Commonwealth is such an one as is equal both in the balance or foundation and in the superstructures, that is to say in her agrarian law and in her rotation. An equal agrarian law is a perpetual law establishing and preserving the balance of dominion, by such a distribution that no one man or number of men within the compass of the few or aristocracy can come to overpower the whole people by their possessions in lands. As the agrarian answerth unto the foundation, so doth rotation unto the superstructures. Equal rotation is equal vicissitude in government, or succession unto magistracy. (...) The contrary whereunto is prolongation of the magistracy which, trashing the wheel of rotation, destroys the life or natural motion of a Commonwealth".
} 
HILL Christopher. The World Turned Upside Down: Radical Ideas During the English Revolution. London: Penguin Books, 1991.

O'FERRAL, Fergus. Civic-Republican Citizenship and Voluntary Action. In: The Common Good. Dublin, n.2 (Spring/Summer 2001), pp. 126-137, 2001.

OSTRENSKY, Eunice. As várias faces de um ator político. In: Revista Latinoamericana de Filosofía. Buenos Aires, v.37, n.2 (Primavera 2011), pp. 167-188, 2011.

POCOCK, J.G.A. James Harrington and the Good Old Cause: A Study of the Ideological Context of His Writings. In: The Journal of British Studies. Chicago, v. 10, n.1, p. 30-48, 1970.

POCOCK, J.G.A. The Machiavellian Moment. Princeton: Princeton University Press, 2001.

SHARP, David. Oliver Cromwell. London: Heinemann, 2003.

SKINNER, Quentin. Meaning and Understanding in the History of Ideas. In: History and Theory. Middletown Wesleyan University, v.8, n.1, p. 3-53, 1969.

SILVA, Ricardo. Maquiavel e o conceito de liberdade em três vertentes do novo republicanismo. In: Revista Brasileira de Ciências Sociais. São Paulo, v.25, n.72, pp. 37-58.

STRUMIA, Anna Maria. Ancient Republics in Seventeenth Century England and the Origins of the Modern Dichotomy Between Authority and Power. In: Hebraic Political Studies. Jerusalem, v. 2, n.3 (Summer 2007), pp. 284-300, 200 